the topological and geometric data associated with industrial pipe systems is significantly faster than entry by alphanumeric encoding through a keyboarrd. The significance of this fact is that faster data entry allows the student or practicing engineer, as the case may be, more time to spend in creative problem solving than in nonproductive data encoding.

One of the objectives of Project C-BE at the University of Texas at Austin is to identify those aspects of CAI which are common to several disciplines and to apply these common concepts on a large-scale basis. Partially on the basis of the results of the above-described study, the project has purchased five interactive graphics terminals for use by students in engineering and science analysis and design courses. These terminals are equipped with light pens which can be used for graphical data entry. These units will allow students to solve graphically related problems such as circuit design, structural analysis, curve fitting, etc., in an interactive mode that is in practice more similar to CAD (computer-aided design) than CAI. One of the results of the project will be the evaluation of long-term use of interactive graphics terminals in CAI applications.

\section{REFERENCES}

Corley, M. R. Graphical data entry in man-machine interactive problem solving MS thesis, Mechanical Engineering Department, University of Texas at Austin, December 1971.

\title{
Using OMNITAB interactively in a statistics laboratory*
}

\author{
JAMES M. SWANSON†, ALEXA LEDLOW \\ and SCOTT HARRIS \\ University of Texas at Austin, Austin, Texas 78712
}

OMNITAB is an interpretive computing system that enables the nonprogrammer to use a large digital computer to perform a large variety of calculations and manipufations on tabulated data without any prior knowledge of computers and computer languages. This language has been used successfully in an undergraduate statistics laboratory, and a description of this use is given. Modifications designed to make OMNITAB more efficient for teaching purposes are also described.

Most psychology departments attempt to teach statistics to both undergraduate and graduate students. In some cases. the result is student frustration. This is understandable, and three obvious reasons why are the following: (1) Typically. students majoring in psychology dislike quantitative topics-they do not like to handle numbers. But students are forced to handle numbers, because homework or laboratory problems are invariably required. (2) If realistic problems are used in the traditional statistics laboratory. repetitious mechanical operations are necessary that are more suited to computers than to humans. This type of numerical problem solving is time consuming, and careless errors are frequent. Most of the student's time, effort, and

\footnotetext{
* This research was supported in part by a grant from the National Science Foundation $(G Y+9340)$ to the Lniversity of Texas, entitled "The Use of Computer Based Teaching Techniques in Undergraduate Science and Engineering Education." This project is codirected by John J. Allan and J. J. Lagowski. The authors gratefully acknowledge the help of $A$. W. Hunt, Mark T. Muller, and Elton Reynolds in this endeavor.

tReprint requests should be sent to James $M$. Swanson, Department of Psychology. University of Texas, Austin. Texas 78712
}

attention is not directed toward learning statistics; instead, it is spent in memorizing short-cut formulas for computational ease, entering and checking numbers at the keyboard of a calculator, and finding and correcting computational errors. (3) If example and laboratory problems are kept small and simple, they are not realistic and the relevance and usefulness of the course is questioned.

At the University of Texas, we are attempting to overcome these problems by augmenting classroom instruction in statistics with an on-line computerized laboratory. Our purpose is to make statistics a more enjoyable and valuable course for both undergraduate and graduate students.

There are three basic objectives in our program. First, we try to overcome the typical student's dislike or fear of handling numbers by providing the student with a "number cruncher." By showing the student how to use a computer, we try to make handling numbers easy and enjoyable rather than frustrating. Second, by introducing the computer as a tool, we are able to use realistic and complex laboratory problems without introducing the boredom usually associated with the mechanical operations of numerical problem solving. Third. we hope to motivate the student by providing a new skill (the use of a computer and a little knowledge about a computer center) that will be viewed not only as immediately valuable and useful in class. but also as having potential applications outside the statistics class.

To accomplish our stated objectives. we needed to teach our students a language that had the following characteristics: (1) It must be very easy to learn. This is very important. because the cost of learning some computer languages in terms of time and frustration is 
greater than the payoff in the statistics class. (2) It must perform all the necessary operations for solving complex as well as simple statistical problems. (3) It must be useful for a variety of problems that students (especially graduate students) encounter outside the classroom in which use of a digital computer would be beneficial. (4) It must be widely available rather than unique to the University of Texas campus.

The language we chose to use is called OMNITAB. OMNITAB was developed and is maintained by the National Bureau of Standards, and it has met all of the requirements stated above. The purpose of this paper is to describe how OMNITAB was used in both an undergraduate and a graduate statistics course, and to describe the basic modifications we have made and plan to make to render OMNITAB a mori efficient teaching device.

The OMNITAB laboratory (OMNILAB) discussed in this paper was designed to supplement any one of three types of classroom instruction available to statistics students at the University of Texas. OMNILAB has been used by the first author in three classes (two graduate and one undergraduate) over the past year in which the traditional textbook and lecture system was used. Plans are being made to incorporate OMNILAB into a self-paced introductory course taught in the psychology department at the University of Texas by Dr. R. K. Young. In this course, a programmed textbook is used, and multiple-choice tests are given. Another type of self-paced course in statistics was developed and is taught by Dr. Gerald Wagner of the mechanical engineering department at Texas. In it, the student selects a module covering a specific topic to be learned. The student is then quizzed by the computer, and the interaction continues until the student has mastered the module. OMNILAB has been designed to be compatible with this course as well as with the statistics courses offered in the psychology department.

OMNILAB, then, is somewhat independent of the first stage of teaching statistics, in which students must commit a set of basic principles and formulas to memory. The second stage of learning statistics, in which the novice statistician tests unfamiliar principles and newly acquired formulas on real problems, is where OMNILAB is designed to be used.

\section{THE LANGUAGE}

OMNITAB is an interpretive computing system that enables the nonprogrammer to use a large digital computer to perform a large variety of calculations and manipulations on tabulated data without any prior knowledge of computers or of computer languages. The OMNITAB master program consists of a set of 177 FORTRAN subprograms which interpret and execute instructions written in the form of simple English sentences. To understand how OMNITAB works, it is helpful to imagine a large worksheet having 50 rows and 20 columns. (The dimensions of the worksheet in
OMNITAB are variable and may be set by the user.) OMNITAB instructions are used to put data into the columns of the worksheet, to calculate using the data, to rearrange the data, and to output the data in various ways. Only the initial word (a command) and the subsequent numbers (arguments) of an OMNITAB instruction are used by the master program, so descriptive comments may be included to aid in understanding the meaning of the instruction. Instructions are executed as they are encountered.

Free formatted input and output and a very simple set of basic instructions make basic OMNITAB as easy to master as a modern hand calculator. The use of these instructions can be demonstrated by the following example: To get data into the worksheet, one merely tells the computer

\section{SET the following numbers into col 1}

and follows the statement with numbers placed anywhere on the card. Commands like ADD, SUBTRACT, MULTIPLY, DIVIDE, SUM, AVERAGE, SQUARE, ORDER, SORT, etc., can be used to perform calculations and to manipulate the data in the worksheet. A simple example is,

\section{SUM the numbers in col 1 and put the answer in col 2}

To print data stored in the worksheet, one merely says,

PRINT the data stored in col 1 and in col 2

A set of higher-order commands [HISTOGRAM, STATISTICAL ANALYSIS, CORRELATION, FIT (least squares regression), ANALYSIS OF VARIANCE, etc.] provide statistical packages designed to handle commonly encountered statistical problems. A complete set of instructions and a description of the OMNITAB system are given in the National Bureau of Standards Handbook 552, OMNITAB II-A User's Reference Manual, by Hogben, Peavey, and Varner (1971). The handbook may be obtained from the Government Printing Office for $\$ 2$.

\section{Examples of Laboratory Use of OMNITAB by Beginners}

A beginning OMNITAB programmer is reminded that each instruction is executed as it is encountered and interpreted, so the order of instructions controls the flow of computations in the same way that hand calculations are performed and recorded in a multicolumnar pad. Students are encouraged to write out the steps of a desired calculation in simple English sentences, and then the list of sentences is taken as the OMNITAB program. For example, the steps for calculating the variance of a set of numbers are 
SUM the numbers

DIVIDE by $\mathrm{N}$

SUBTRACT the mean from each number

SQUARE the resulting deviation scores

SUM the squared deviations

DIVIDE by $\mathrm{N}-1$

If the concept of a worksheet is added to keep track of the numbers, then the OMNITAB program is complete. To illustrate the use of basic OMNITAB, the instructions and a solution for a laboratory problem are presented in Table 1. This laboratory problem was assigned to 50 undergraduate students (mostly sophomore psychology and nursing majors) in an introductory statistics class. These students had completed a week of class, during which the topics of frequency distributions and summary statistics were covered in lecture and in the assigned chapters in the text. All except 5 were completely naive in regard to computer use or computer languages. A short $(30 \mathrm{~min})$ description of how OMNITAB works was given in class, and students were given a copy of the basic set of instructions to be used.

The laboratory work was done in a classroom provided by the Computer Based Education Project at Texas, which is funded by the National Science

Table 1

An Example Laboratory Exercise. Lab 1: Using OMNITAB to Calculate Summary Statistics. Teletype output is given below. The lines below enclosed in quotation marks were entered by the student: the other lines were initiated by the computer. The OHNHTAB commands and arguments are underlined for the reader's benefit. The other words in the instructions are ignored by the computer; they could be left out, but they prove to be powerful mnemonic aids to the novice user.

\begin{tabular}{|c|c|}
\hline 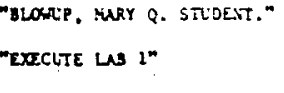 & 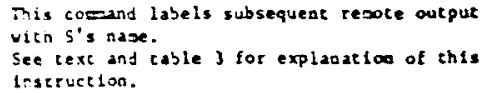 \\
\hline
\end{tabular}

INSTRCCTIONS. TE $91 \times$ A $X$ Y SCORES CLEX ON P. 100 OF "BASIC STATISTIC BY 'i. L. HAY

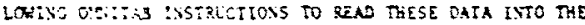
OCDITAS WORTISETT.

FORMAT \& $(F 2.1,53.0)$

RE:TSO TAPE A

CREA TAPE A B FORYAT $91 \times$ ANS Y SCORES I:TO COLS 1 ANO 3

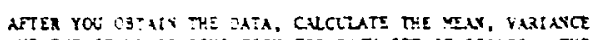

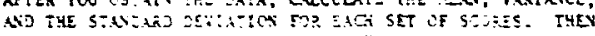
LSE TIE "Te

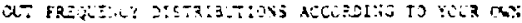
SPECIFICAITLSS.

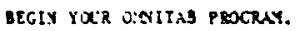

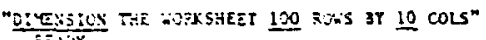

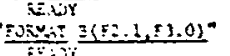

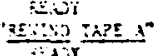

"Cacon

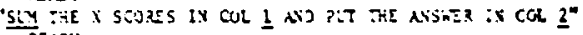

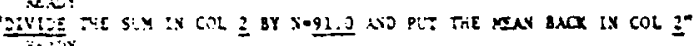

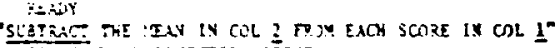

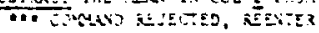

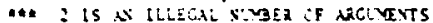

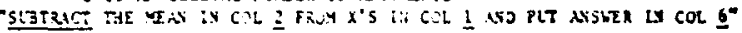

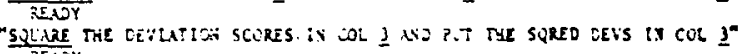

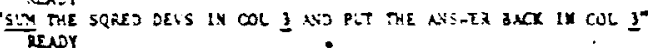

"DIFIDE COL 3 EY 00.0 ATO PLT THE AFERACE SRYARED DEV IN DOL $\underline{3}^{\text {" }}$

"SSRT OF THE VARTANCE IS COL 3. PLT THE ANSLER (STO DEV) INTO COL \&"

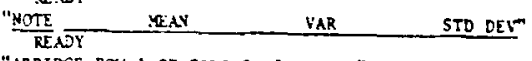

"ABRIXCE ROW 1 of COLS 2. 3, NHD 4 "

RENOY $4 . \overline{1} 978022$ - $3.0158 \overline{1} 93 \quad 1.7366115$

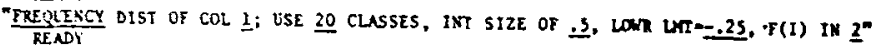

"SET MIDPOLNTS IS COL 3"

SET MIDPOY

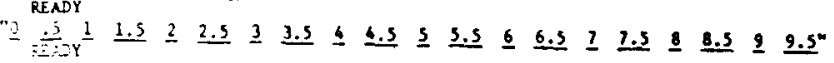

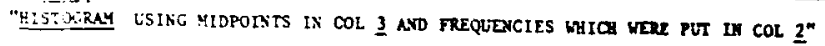

$x: 2-90175$

rREQtexC

0.

.50000000

$\therefore .0000000$

1.5000000
2.5000000

2. 530000

3.0000000

3. 3000000

$\because .5000000$

5.0300000

5.5000000

t. 0000000

c. 5000000

.0005000

. 5050900

$\div .3200000$

9.500000

0,5000000

드:

"PQIVT THERE" This directs printed output to printer at the Computer Center ratier thin to the user's local terninal. This

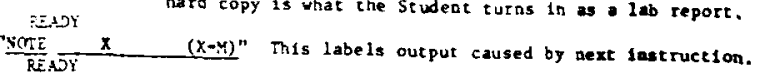

$+t+t+t+t+t+t$

$+++++t++$

$+++++++++++++t$

$+++++++++++t+$

$+++$

$+++$

$++t+$

$+t+t+$

$+t+$

$+++$ "PSTT COLS 1 AND $6 "$ This prints out the 91 rav scores and deviation scores.

NSAV YAR STP LEV" This labels output of next instruction.

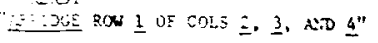

The nex: two instructions print out what the Studenc had inspected earlier
on the display.

JR+44 MID PIS IX 3, FREQS IN 2"

"EII:T HERE" This cells the computer to direct printed output to user's tervinal once azain.

The procedure wold be used to obtain sureary statistics and a Erequency distribution for the $Y$ scores.

Foundation. The room is equipped with five DataPoint terminals. which have CRTs as display devices and which operate at 10 characters/sec. The laboratory sequence follows:

12:00 noon Five DataPoints are turned on, and the instructor logs in using the class number.

Data files are read. and OMNITAB is requested.

12:05 A READY signal indicates that OMNITAB is ready to go.

12:05-3:30 Students arrive at their convenience and have to wait a short while to get on a terminal. To start. a student issues a system command to label output directed to a line printer. Each student takes about 15-20 min to work a laboratory problem assigned previously in class. 
After obtaining a solution to the lab problems on the screen, the student asks OMNITAB to print out the solution at the computer center or at a nearby line printer.

The student then walks across the street and picks up the output. Additional work is done on the output, and then the output is turned in as a lab report.

Laboratory is over. All psychology students clear out.

The first laboratory session was monitored by the first author, and the following statistics were calculated: Number of students attending lab-47: number of students completing lab-47; average time per student on terminal-20 min; average cost per student-\$.38.

Students were graded on a pass/fail basis for lab work. A completed and correct computer output. appropriately labeled, was required to receive a passing mark for the lab.

We were surprised to find that every student used OMNITAB effectively during this first session. Most students made mistakes in entering OMNITAB commands, but the error messages which immediately follow improper instructions allowed the student to make self-corrections. This immediate feedback aspect of OMNITAB makes the language almost self-teaching. The first five students on the terminals needed aid from the lab supervisor to get started; subsequently, students watched the preceding user and this acquired familiarity resulted in very few appeals to the supervisor for aid. A few complaints were voiced, mostly concerning slow response time on the time-sharing system, but almost all of the students seemed to enjoy the lab.

A later laboratory of the same introductory class (which was also an assignment in a graduate statistics course following a lecture on regression and correlation) is shown in Table 2.

Since this lab was during the second half of the course, it was assumed that students knew how to calculate simple summary statistics like $b_{x, y}, r_{x, y}, s_{x}$, and $s_{\mathbf{y}}$, so these statistics were calculated automatically and stored on the worksheet using higher-order commands (CORRELATION, FIT, and STATISTICAL ANALYSIS) rather than by step-by-step calculation. The use of these higher-order commands allows the emphasis in laboratories concerning advanced topics to be placed on the relationship among various statistics rather than how to calculate them.

Again, all of the students who attended the lab produced a correct output (some on the second try). The average terminal time per student was less than $30 \mathrm{~min}$, and the average cost per student was less than S.45.

The example labs given in Tables 1 and 2 are 2 of the 10 labs being developed for the OMNILAB sequence.
Table 2

Lab 7: Using High-Order Commands (CORRELATION and FIT) to Show the Relationship Between Regression and Correlation. The following describes the output automatically obtained when these instructions are used: see OMNITAB II: U'ser's Reference Hamual for exact copy of the auto-output.

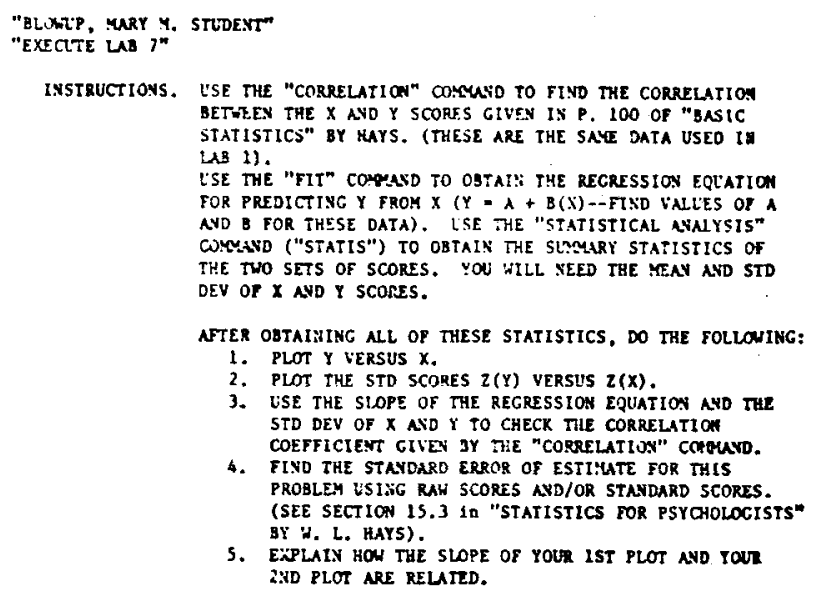

THE $91 \times$ AND $Y$ SCORES ARE IN COLURS 1 AND 5.

THE WORKSHEET IS 100 RU'iS OT 10 cots.

BEGIS YOCR OYWITAB PROGRAY.

"CORRELATION OF $\underline{2}$ VARIABLES In COLS 1 ND $\underline{\text { s" }}$

This comand produces automatic prtineing of stople, partal a and rat correlacion astrices plus significance levels and confideace intervals

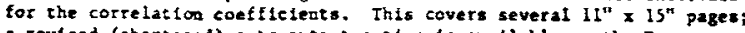
- revised (shorteaed) auto-outpot option is avallable on the Texas versiod of OWIItAs.

READY "DETTME 1.0 INTO COL 2 "

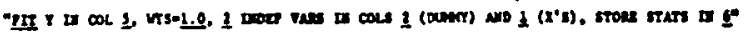

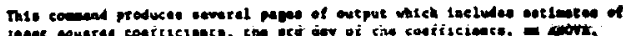

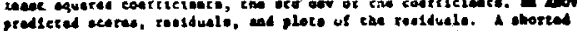

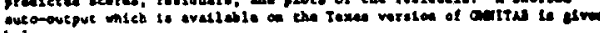
mien.

r - 1.13518 + s.41ent (21)

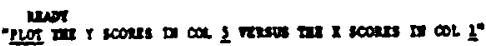

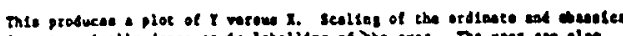

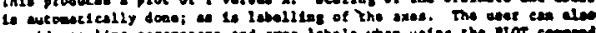

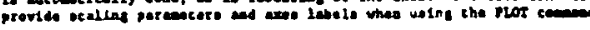

IENor

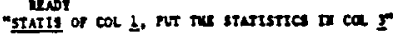

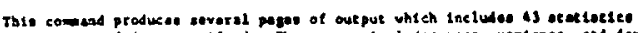

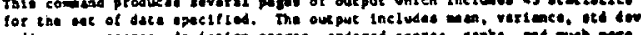

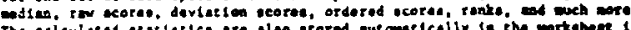

The calculactal alationse

newer

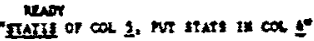

outpor

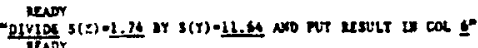

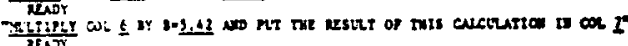

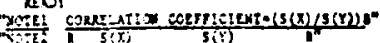

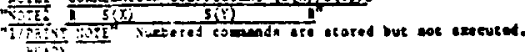

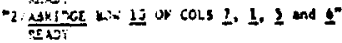

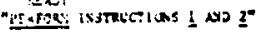

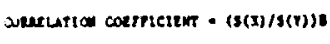

$i s(x) \quad s(r) \quad$,

Lis

"SiLARE THF RESIELALS STORED IN COL 7 AND PLT IN COL $\underline{8}^{\prime \prime}$

Tititi

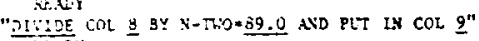

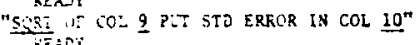

"IBRIDCE STATDARD ERRUR OF ESTIMATE FROM RCW 1 OF COL 10"

6.32

RSADX
"STOP" 
The complete set of 10 labs include the following: (1) frequency distributions and summary statistics. (2) standard scores. (3) the normal distribution. (4) sampling distributions and t. (5) chi square and r. (6) correlation. (7) regression. (8) F distribution, (9) ANOVA I. and (10) ANOVA II. A laboratory manual and a simplified instruction manual for OMNITAB are being developed as part of the Computer Based Education Project at Texas. Both manuals are being developed for undergraduate classes. and the manuals will be evaluated and tested during the spring and summer of 1973.

\section{Modifications of OMNITAB}

The basic modification of OMNITAB at Texas is the interactive version deveioped for use on remote terminals under the time-sharing system called TAURUS. Scott Harris (1971) of the University of Texas Computation Center did the necessary modifications to implement the time-sharing version. Since using OMNITAB interactively allows the student to have immediate feedback concerning calculations and errors, it is almost a necessity for efficient use of OMNITAB as a teaching tool. The unavoidable wait between submission of a job in the batch-processing mode and the eventual output tends to discourage students from using the computer: the interactive mode tends to provide a motivating force that encourages rather than discourages students in their use of the computer.

A second modification of OMNITAB is planned to make the system a more versatile teaching device. The proposed modification is called a CHECKPOINT routine. It is designed to allow an instructor to initialize the OMNITAB program with stored instructions and to initialize the worksheet with instructions and data. For example. using the CHECKPOINT routine. a set of commands could be stored by the instructor that read the data from a tape to the worksheet. Such a set of commands could be executed by a single statement. such as

\section{EXECUTE problem 10}

This would initialize the worksheet and give instructions to the student. as shown in Table 3 . The addition of the CHECKPOINT routine would allow OMNITAB to be used in a completely self-paced manner.

Anticipating the use of OMNITAB in a large self-paced class. a record-keeping and grading routine has been designed. To use the recorder/grader. each student must write selected answers to laboratory exercise onto a tape. The tape then is processed by a recorder grader program developed by Dr. Jan Bruell. The complete class roster is derived from tapes processed in this way. Initially. OMNILAB was being developed as a supplement to the textbook lecture method of
Table 3

Using the Checkpoint Routine Available in The University of Texas Version of OMNITAB to Store Commands. The first set of commands would be prepared by the instructor and would be part of the OMNITAB system the student gets by requesting OMNITAB. This set of commands was prepared assuming that the data and instructions to be printed out and used by the student are already on tape.

THE INSTRLTTOR'S PROGNY

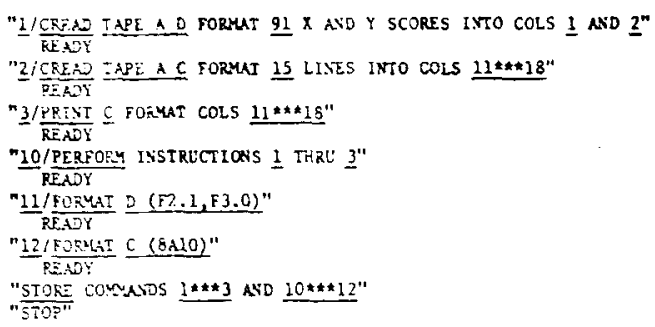

TEE STLDENT ${ }^{*}$ OWITAB PROGRY

"EXeCUTE PSOBLE NTMER 10"

This would result in the worksheet betng initialized and instructions siailar to those given at the $u p$ of table 1 or 2 being printed out to the user. Fuliowing the lire "BEGIN OWITAB PROGRA", the user vould start work and vould continue as show in table 1.

instruction; the second phase of using OMNITAB as a teaching device will be directed toward using OMNITAB in a self-paced manner.

\section{A Summary of the Desirable Features of OMNITAB}

The laboratory examples shown in Tables 1 and 2 indicate how OMNILAB is a useful teaching aid in a statistics lab. First. the problem of entering data on a keyboard is overcome by storing a set of data on a tape. A student then can just ask for the data (and print them out to see them) rather than manually entering each number. Second. using OMNITAB. a student can work a problem using the same steps required by hand calculation. except now there is no chance of careless errors in performing the calculation (thanks to the error free number cruncher which is controlled by OMNITAB). Third, OMNITAB can give immediate feedback following calculation: if a student wants to view an answer. he merely asks to see it displayed. Fourth. when OMNITAB is used. more realistic and complex problems can be used that are unreasonable in a noncomputerized lab: and. because of the speed of OMNITAB. more problems can be assigned and worked during each laboratory session. And fifth. a neat, readable copy of the students' lab work can be easily obtained. even if CRT displays are used. by asking for a printout at the central computer center.

OMNITAB has other desirable features. It is easy to learn. Sophomore psychology students can use OMNITAB to work a laboratory problem (see Table 1) in the same laboratory session in which they are introdused to the computing ststem. Also. the system and he used for solving omplex statistical problems 
either by programming the step-by-step procedure or by using the statistical packages provided.

Finally, a very important benefit of using OMNITAB in a statistics laboratory is that psychology students are introduced to the computer center. Students not only are aided in learning statistics: their experience also dispels many misconceptions of what a computer does, and it provides some basis for understanding how computers affect their lives.

\section{REFERENCES}

Harris, S. $L^{+}, T$. O.MNITAB II, version 5.0: $L^{\dagger}$ ser's reference monual supplement. Austin, Texas: University of Texas Computation Center, TPB-132, 1971.

Hays, W. L. Statistics for psychologists. New York: Holt, Rinehart, \& Winston, 1963.

Hays, W. L. Basic statistics. Belmont, California: Brooks/Cole, 1969.

Hogben, D., Peavy, S., \& Vamer, R. OMNITAB II: L'ser's reference manual. (National Bureau of Standards, Technical Note 552). Washington, D.C: U.S. Government Printing Office, 1971 .

\section{Teaching young children how to use a computer-based Teletype as a "desk calculator"}

\section{ELIZABETH F. LOFTUS* \\ New School for Social Research. New York, New York 10011}

The first stage in the research reported here was to teach students the mechanics of how to use a computer-based Teletype as a "desk calculator" in the solution of arithmetic problems. In the second stage, we examined a specific use for the desk-calculator program: we presented a series of word problems to the students and analyzed the solutions of these problems to determine the variables related to problem difficulty.

At Stanford University, the Institute for Mathematical Studies in the Social Sciences (IMSSS) has been developing over the last 9 years a working computer-assisted instruction (CAI) system for classroom use. The research reported here is a small part of a continuing investigation on the potential use and value of such systems. This paper summarizes two demonstrations of a new use for CAI systems.

The demonstrations both involve a computer program which was used to teach bright fifth-grade students, in one case, and disadvantaged sixth-grade students, in the other case, how to use a computer-based Teletype as a desk calculator. Assuming that the students had a basic understanding of the four arithmetical operations (addition, subtraction, multiplication, and division), we asked them to tell the computer which operations they wanted the computer to execute. The actual computations, then, were done by the computer itself.

This report is divided into two major sections. In the first section, we describe the mechanics of how students were taught to use a computer-based Teletype as a desk calculator. In the second section, we describe one use for the desk-calculator program: an analysis of problem-solving performance.

*Requests for reprints should be sent to Elizabeth $F$. Loftus, The Graduate Faculty, New School for Social Research, 66 West 12th Street. New York, New York 10011.

\section{THE DESK-CALCULATOR PROGRAM}

The student terminals used in this project were commercially available Teletype machines, connected by private telephone lines to a computer at the Institute. The control functions for the entire system were handled by the PDP-1, a medium-sized computer with a 32,000-word core and a 4,000-word core interchangeable with any of 32 bands of magnetic drum, together with two large IBM-1301 disk files. All input-output devices were processed through a time-sharing syctem. Two high-speed data channels permitted simultaneous computation and servicing of peripheral devices.

Initial instruction on the Teletype consisted of explaining to each student what the program was generally about. Each student was then given assistance in finding the letters to type his name; no student had any trouble learning how to do this. The program began each day by asking the student to type his assigned number and his name. If the student made an error or gave a fictitious name, such as Napoleon, he was asked to try again. If he typed his number and name correctly, the computer consulted his file and began with the item following the last one completed.

A set of instructions presented via computer taught the student how to command the computer to perform operations on given numbers. The complete set of instructions is given in Loftus (1970). Here, we will briefly list and give an example of each of the abbreviated operation names that the student learned in the instruction set. Student entries are underlined.

(1) $X$ is the answer key.

Suppose the student saw on the printout sheet before him:
G 1) 19 